\title{
ELEIÇÃO 2010: DESMORALIZAÇÃO ELEITORAL DO MORALISMO RELIGIOSO
}

\author{
ANTÔNIO FLÁVIO PIERUCCI
}

\section{FATOR RELIGIÃO}

Não lembro, e certamente ninguém há de lembrar, de uma campanha eleitoral em que a intromissão da religião tenha sido tão grande e ido tão longe como na eleição presidencial de 2010 para a sucessão de Lula. Ingerência tão intensa e tão extraordinariamente inflamada, pra quê? Para tentar deter no voto popular a escalada ao podercentral da nação de uma mulher sem Deus, que por falta de religião e visão minimamente decente da criatura humana iria querer, se eleita presidente, legalizar o aborto e criminalizar a homofobia. Denúncias e mais denúncias com provas documentais lançadas em avalanche dos púlpitos e na internet. Seu núcleo duro: declarações de Dilma, anteriores à candidatura, expressamente favoráveis à descriminalização do aborto, acompanhadas da recapitulação exaustiva de todas as tomadas de posição constantes de textos petistas (do partido e do governo), com destaque para os projetos de modernização jurídica visando a ampliar ainda mais os direitos das mulheres como cidadãs autônomas e calçar legalmente a plena cidadania dos homossexuais. PL 122 e PNDH-3? Enormidades! Hora de juntar forças do lado do Bem para exigir com a voz das urnas maior espaço para Deus na vida pública da nação.

Sociólogo da religião, senti a cobrança de colegas e alunos, mas vinda também de dentro de mim mesmo, para "escrever a respeito de tanta religião assim nessa eleição", conforme se expressou uma estudante. Aí chegou o convite da Novos Estudos, e tratei logo de ir reler recortes de jornal e percorrer de novo a internet em busca de um ponto focal onde ancorar meu argumento.

Foi estranho. Logo que aceitei contribuir para a discussão dos efeitos do fator religião no jogo político-partidário com um artigo dedicado ao papel que a religião desempenhou na cena eleitoral de 2010 (na verdade um papelão, para ser mais exato), pensava em falar mais uma vez do mesmo, isto é, da força que a partir do restabelecimento da democracia nos anos de 1980 a religião passou a ter nas disputas eleitorais neste país. 
Isso ocorre pelo menos desde a eleição de 1986 para o Congresso Constituinte. Desde então ficara combinado que a investida religiosa em processos eleitorais para produzir votos é efetiva e eficaz. Sobretudo quando se contenta em carrear para candidatos que são eclesiásticos de profissão o voto do eleitor religioso socialmente conservador. E ser socialmente conservador, já sabemos, não é prerrogativa exclusiva do bon peuple católico. É também uma das características ideológicas do eleitor evangélico típico, e nesse modo de ativismo eleitoral também já sabemos que os pastores evangélicos ficaram mais escolados e autoconfiantes. Com sucesso mais garantido, porém, só quando tomam parte em disputas para cargos parlamentares. Estão aí como prova as tais "bancadas evangélicas" que se formam desde 1986 na Câmara Federal, nas assembleias legislativas e câmaras de vereadores.

Num país de paisagem católica, não faltam políticos evangélicos nos diversos níveis do poder legislativo. Nessas instâncias, próprias da política parlamentar, só mais recentemente é que se fez notar a marca dos católicos declarados. Não necessariamente progressistas, muito pelo contrário, indício de que no conjunto do catolicismo brasileiro chegou mesmo a vez dos conservadores assumidos. Às vezes tão conservadores, que surpreendem pelo forte teor retrógrado de suas tomadas de posição.

\section{Crença abalada}

Pelas lembranças que eu guardava da temporada eleitoral de 2010 , pensei que ao me reportar a ela com redobrada atenção para traçar esta análise eu ia sair mais convencido da importância realmente existente do voto religioso em nosso país. Mas não.Acabei concluindo o contrário.

Começo, pois, estas considerações declarando que, das perguntas em que mergulhei enquanto repassava e, não raro insatisfeito, para não dizer inseguro, voltava a repassar as pastas de recortes de notícias e comentários tirados de jornais e revistas, sites e blogues da internet que ajuntei ao longo da campanha eleitoral à presidência, volto desses mergulhos interrogantes com pelo menos uma certeza nova: a de que a velha certeza, nem tão antiga assim, que pairava no ardesse ambiente de comentaristas políticos e cientistas sociais que frequento e que era dada por muitos desses observadores profissionais como praticamente definitiva num país religioso como o nosso saiu da última eleição presidencial bastante abalada. Até ontem, era como se entre nós brasileiros tivesse sido posto fora do alcance de toda dúvida, à maneira de uma evidência que aos olhos saltasse, o fato de que religião "realmente funciona" quando se mete em dis- 
putas eleitorais, crença difusa que entretanto segue com fôlego de atleta junto aos que são a favor, mas também entre os que são contra misturar religião com eleição.

Sinais evidentes (poisé, evidentes!) de que ovoto religioso existe e é poderoso não faltavam. Por exemplo, a derrota de Jandira Feghali (do PC do B) na eleição para o senado pelo Rio de Janeiro em 2006 como que cristalizou essa forma de certeza nos arraiais de esquerda e centro-esquerda, corroborando-a de uma vez por todas e com toda sorte de penduricalhos míticos. Sua derrota é reportada até hoje como prova indiscutível de que o voto religioso, uma vez mobilizado contra um alvo definido, tem força sim. Ainda mais quando o alvo mirado é uma "candidata abortista", e o eleitorado religioso é açulado por ativistas profissionais full-time a soldo das globalizadas agências do fundamentalismo pro-life, como foi o caso com Jandira e, temia-se, poderia se repetir com Dilma. No caso de Jandira, seus partidários juram até hoje que foi o voto católico o grande causador de sua debacle, alegada prova dos nove de que no lado conservador do eleitorado o apelo religioso funciona.

Pelo sim pelo não, o dado cultural que aqui interessa sublinhar é que até o final de 2010 , a bem dizer até ontem, estava sossegadamente instalado no folclore político brasileiro, em paralelo à sua vigência inquestionada entre os formadores de opinião, ou seja, no comentário político profissional e espontâneo, erudito ou de senso comum, um pressuposto no sentido forte da lógica clássica: uma premissa que não pede para ser enunciada. Essa presunção tácita até agora hegemônica é a de que no Brasil vigora o voto religioso, esse místico dispositivo democrático mitologicamente dado como certo ou mais que certo, certeiro, posto que incitado, quando não intimado, por profissionais religiosos por definição munidos de ascendência moral e doutrinária sobre os fiéis.

A falácia que calça o assentamento dessa inquestionada certeza consiste em tomar como equivalente ao voto das massas religiosas o envolvimento eleitoral dos profissionais da religião (padres, pastores, bispos católicos e evangélicos, até o papa se necessário) seja a favor ou seja contra um dos lados da disputa, mas no fundo sempre em favor da sobrevida da dominação religiosa na totalidade social.

Ovoto das massas religiosas não há de ser necessariamente umvoto obediente, essa desfiguração odiosa da figura libertária do voto secreto. Voto, se for obediente, submisso a poderes hierárquicos e corporativos como os dos chefes de comunidades religiosas, será a negação prática de uma faculdade essencial do sufrágio universal: a virtude de emancipar politicamente o indivíduo dos "podres poderes", e essa liberdade precisa da intransparência do voto desferido individualmente na cabine eleitoral indevassável. Voto obediente é contradição performática. 


\section{EFEITOS PERVERSOS}

Com que então a religião no Brasil tem o condão de se tornar uma força popular em época de eleição? "Devagar com o andor!" - é o recado de 2010 . Tudo se passou na última eleição presidencial como se um trickster abruptamente houvesse destampado a garrafa e libertado no meio do redemoinho da campanha eleitoral um gênio funéreo capaz de enrolar o prestígio da religião num imbroglio de surpresas decepcionantes extremamente desconfortáveis. Ao frustrar os desígnios utilitários de quantos pensavam poder fazer dela um uso estratégico de previsíveis resultados favoráveis, a religiosidade conservadora das massas pregou uma peça no desabrimento dos que a convocaram a desempenhar papel decisivo na sucessão de Lula.

Em jargão weberiano, uma ocorrência como essa é o que se chama "consequência imprevista ou indesejada". É o também chamado paradoxo das consequências, que recebeu na sociologia de Weber a seguinte definição: "a relação paradoxal entre a vontade e os efeitos que ela produz: o problema do homem e do destino (o destino como consequência da ação do homem contra suas intenções)" 2 . Aplicado tal paradoxo ao andamento do segundo turno da campanha de 2010 , foi como se um estratagema racionalmente hierarquizado a fim de otimizar a votação no candidato da oposição se visse atropelado por uma aflitiva irrupção do irracional no curso encadeado de ações arquitetadas dentro da maior racionalidade técnica. A língua da sabedoria popular fala em "ironia do destino". Na sociologia francesa, o nome corrente é "efeito perverso"3.

Ao reexaminar passo a passo o segundo turno da campanha à sucessão presidencial tendo sempre o foco voltado para o lado que terminaria derrotado, um dos efeitos eleitorais da religião que desse ângulo consigo flagrar pertence claramente ao gênero efeito perverso 4 . Existem diversas classes de efeito perverso, e uma das já catalogadas é o "efeito bumerangue", que acontece quando a consequência adversa advém sem mais demora, quase em cima da ação praticada. Seu timing de incubação é ligeiro, adequado pois à brevíssima duração de um segundo turno de campanha eleitoral.

Vejamos.É consenso entre os analistas que no primeiro turno o destaque dado à ausência de prática religiosa na biografia de Dilma como explicação de suas posições abortistas (somado à expressiva votação da candidata verde) contribuiu para prolongar por mais um turno a disputa pela vaga presidencial. Ponto, portanto, para os que apostavam na força do voto religioso. Só que, nem bem definidos os rumos que o segundo tempo da peleja iria tomar, do ponto de vista teórico privilegiado neste artigo não há como não pontuar
[1] Weber, Max.A ética protestante e o "espírito" do capitalismo. São Paulo: Companhia das Letras, 2004, p. 81.

[2] Idem. The religion of China: confucianism and taoism. Glencoe: The Free Press, 1951, p. 238.

[3] Cf.Boudon, Raymond.Effetspervers et ordre social. Paris: PUF, 1977.

\footnotetext{
[4] Alguns cientistas sociais brasileiros preferem dizer "efeito reverso". $\mathrm{O}$ adjetivo "reverso" de fato soa mais explicativo, deixa o sintagma menos sibilino que o adjetivo "perverso".
} 
[5] Powell, Larry e Neiva, Eduardo. "The pharisee effect: when religous appeals go too far". Journal of Communication and Religion, vol.29, 2006, pp. 70-102.

[6] É desse novo dispositivo conceitual que aqui me valho para amarrar estas notas que escrevi para um começo de conversa. Foi há pouco mais de dois anos que essa noção chamou minha atenção, quando lia a cobertura da eleição presidencial americana de 2008 feita pela revista Carta Capital. Ao repercutir análises feitas nos Estados Unidos sobre o insucesso da candidatura ultraconservadora de Sarah Palin, uma das matérias da revista dava justo destaque ao efeito fariseu. que exatamente por ter saído reavivado do primeiro turno o entusiasmo em relação ao peso do voto religioso-antiaborto, uma reviravolta estava prestes a se dar. E, em prazo muito curto, aos olhos ansiosos da oposição o apelo religioso no segundo turno passaria de trunfo a estorvo.

Efeito bumerangue é assim: o que vai não tarda a voltar. Do momento em que a confiança adquirida induz o condutor a forçar o pé no acelerador, pode lhe escapar das mãos o controle da direção. Perde-se o domínio sobre o curso de uma ação estratégica racionalmente planejada passo a passo, presumidamente controlável em seu avanço escalonado. Nem bem se captam os sinais do desastre iminente, quase nada resta a fazer, a não ser, no caso de uma campanha eleitoral pela tevê, disfarçar em público e lamentar nos bastidores o backfire sofrido, o tiro que saiu pela culatra.A próxima rodada de pesquisas de intenção de voto será implacável ao mostrar em números o tamanho da rebordosa.

\section{“EFEITO FARISEU”}

Americanos costumam ter classificação para tudo. Posto que a categoria efeito bumerangue não satisfizesse até o fim o interesse de conhecimento dirigido para a delicada relação que se apronta quando política e religião se entrelaçam num processo eleitoral, a pesquisa social norte-americana, não faz muito tempo, isolou uma classe ainda mais específica de efeito perverso do grupo bumerangue: o "efeito fariseu". O termo passou a existir na sociologia política norte-americana há pouquíssimo tempo, quando usado em 2006 por uma dupla de psicólogos sociais da Universidade do Alabama, estudiosos de pleitos eleitorais, Larry Powell e Eduardo Neiva5.

O fenômeno sociopolítico descrito com esse nome de sonoridade bíblica despontou quando os dois pesquisadores analisavam o insucesso do republicano Roy Moore em sua candidatura ao governo do Alabama, depois de uma campanha toda feita à base de argumentos e apelos religiosos. A quintessência de sua campanha estava fincada na apresentação de si como alguém extremamente religioso, justo e moralmente justiceiro. Para se ter uma ideia, a campanha de Moore vinha compactada no seguinte slogan alusivo ao seu rigor religioso: O juiz dos Dez Mandamentos. Deu zebra. Segundo Powell e Neiva, o que ocorreu foi que ele se deixou atropelar por um efeito fariseu, que é quando a ventilação eleitoral de temas, critérios e apelos religiosos obtém do eleitor conservador resposta contrária à esperada ${ }^{6}$.

Efeito fariseu, portanto, é uma família muito particular de efeito perverso da classe bumerangue, cujo solo mais propício é a par- 
te conservadora do eleitorado, certamente a mais suscetível de ser persuadida por argumentos religiosos. É um evento que se precipita em disputas políticas quando os apelos à religião se excedem, vão longe demais do convencionalmente admissível, mas principalmente - eis aí o efeito fariseu por antonomásia - quando o mote da persuasão desliza para a "personalidade religiosa" do candidato. O caso do famigerado "santinho", em que a foto de Serra vinha encimada pela sentença "Jesus é a verdade e a justiça" e trazia a assinatura dele foi, pode-se dizer, como um tiro no pé com sequelas fatais. Um fervor cristão assim tão personalizadamente ostentado mostrou-se de imediato inconveniente, esquisito, incapaz portanto de seguir sustentando de modo persuasivo seus ataques a Dilma como candidata sem religião nem jeito para a coisa. Consumava-se aí um caso óbvio de uso eleitoral da religião repercutindo como abuso na recepção.

Minha hipótese, como se vê, é que na eleição do ano passado para a sucessão de Lula o Brasil assistiu a um caso de efeito fariseu, e aqui, tal como lá nos Estados Unidos, sua eclosão só podia se dar no campo conservador. Hoje a sociologia política já pode contar com essa categoria descritiva que ilumina como nenhuma outra uma importante faceta da última campanha presidencial brasileira, convidando-nos a fixar o foco no lado perdedor, cuja campanha apostou pesado em argumentos de fundamento religioso com o fim de motivar a adesão (ou a fidelidade) do eleitor conservador. E exatamente como Roy Moore, por apostar nesse tipo de argumento José Serra não resistiu à tentação de representar em público a persona do candidato "mais religioso". O que dizer de um QG de campanha que esteve o tempo todo inexplicavelmente desavisado da possibilidade objetiva de que ocorresse esse tipo de efeito reverso já detectado e analisado nos Estados Unidos desde 2006 ?

\section{O fariseu e o pUblicano}

O apelo religioso de viés moralista, já foi dito, visa diretamente ao eleitor conservador, esse ser presumivelmente mais sensível a uma interpelação de caráter religioso. $\mathrm{Na}$ avaliação de grande parte dos observadores do processo, a apuração das urnas do primeiro turno mostrou que a investida religiosa havia funcionado conforme o planejado, beneficiando o lado declaradamente religioso da disputa. Transcorrido pouco mais de um terço do segundo turno, pouco antes da metade, o mesmo expediente começou a dar sinais de fadiga. A religiosidade pessoal de José Serra, até então apresentada na campanha como mais vigorosa e mais verdadeira do que os baixos teores de convicção e prática religiosa da guerrilheira Dilma, 
[7] O Evangelho de Mateus (Mt 23,13-32), para mostrar que Jesus costumava acusar os fariseus de hipocrisia, vale-se da figura de uma anáfora repetindo em seis inícios de frase a maldição: "Ai de vós, escribas e fariseus, hipócritas!”. por causa da obviedade de alguns exageros deu de ser captada como postiça. Puro fingimento, para não dizer hipocrisia, essa desvirtude própria do fariseu da parábola com a qual Jesus tipificou dois estilos de ser religioso, o fariseu e o publicano. A breve parábola consta do Evangelho de Lucas:

Dois homens subiram ao templo para orar; um era fariseu e o outro publicano. O fariseu, de pé, orava de si para si mesmo desta forma: "Ó Deus, eu te dou graças porque não sou como os demais homens, ladrões, injustos, adúlteros, e nem ainda como esse publicano; jejuo duas vezes por semana, dou o dízimo de tudo quanto ganho."O publicano, mantendo-se à distância, não ousava sequer levantar os olhos ao céu, mas batia no peito dizendo: "Meu Deus, tem piedade de mim, pecador!" Eu vos digo que este desceu justificado para sua casa, e não aquele:porque todo o que se exalta será humilhado, e quem se humilha será exaltado (LC18,10-14).

O fariseu é retratado como um homem orgulhoso de sua prática religiosa, em contraste com o humilde publicano que, contrito e cabisbaixo, só sabe pedir a Deus o perdão de seus pecados. No versículo imediatamente anterior ao início da parábola (LC 18,9), o evangelista afirma que Jesus endereçou essa narrativa alegórica àqueles que, como os fariseus, confiam em si por se considerarem justos, fazendo-se passar por santos diante dos outros. Na figura rastaquera do fariseu, Jesus recrimina todo aquele que faz pose de muito devoto por fora enquanto por dentro só faz alisar o próprio ego como se aos olhos de Deus fosse mais pio que o resto dos mortais. Age, pois, feito um fariseu hipócrita7 quem faz demasiada publicidade da excelência de sua própria religiosidade, que é apenas aparente. Segundo os Evangelhos, o erro moral do fariseu é o de instrumentalizar a visibilidade de sua exuberância religiosa com o fim de turbinar a própria imagem pública. Em cima, Jesus vaticina: "Quem se exalta será humilhado" (LC 18,14; Mt 23,12).

Segundo seus formuladores, o conceito de efeito fariseu foi terminologicamente plasmado a partir dessa parábola justamente para mostrar que, uma vez levadas na devida conta pelo pesquisador as disposições religiosas do eleitor conservador, é possível apreender os limites que há para a religiosidade enquanto ingrediente de táticas eleitorais. No caso da eleição presidencial brasileira de 2010 , a noção de efeito fariseu traz a vantagem de sugerir fortemente que foi a percepção, pelo eleitor conservador, de excessos no emprego tático da religiosidade pessoal de Serra que estancou suas chances de subir nas últimas pesquisas e o fez estacionar numa posição de desvantagem em relação à concorrente sem religião nem humanidade. 
Fácil entender como ocorre um efeito fariseu quando se atenta para certos aspectos constitutivos de toda campanha eleitoral para cargo executivo, notam os formuladores dessa teorização que envolve abstrações bastante próximas dos dados observados. Campanha eleitoral para cargo executivo constitui uma modalidade muito especial de jogo político institucionalizado. Além de ter começo, meio e fim estritamente delimitados por um calendário de curta duração, o jogo deve ser disputado em grande parte à base de interpelações mútuas entre os concorrentes. Quando estão previstos dois turnos, então, com apenas dois concorrentes permanecendo no segundo tempo do jogo, a disputa doravante bipolarizada entre concorrentes alçados à condição de antagonistas propriamente ditos faz subir o tom confrontativo das interpelações recíprocas, que, com carga energética aumentada, se exteriorizam na forma de ataques e contra-ataques não só de teor estritamente político ou programático, mas principalmente de caráter pessoal, ficando impossível não partir para acusações diretas à pessoa do candidato antagonista e à sua, discutível, trajetória de vida.

Nesse clima de ânimos exaltados e acusações em escalada, nesse contexto de inescapável comparabilidade mútua entre duas personalidades e duas biografias, a possibilidade concreta de um efeito fariseu em boa parte já está armada. Fica a depender apenas de que uma das partes - de regra o candidato do lado conservador - venha a utilizar como arma de ataque, feito faz o fariseu, a vantagem de suas convicções e práticas piedosas, numa palavra, sua religiosidade pessoal. $\mathrm{O}$ ingrediente religioso vai tornar o confronto ainda mais personalizado, e o risco ilusoriamente calculado de partir com tudo para uma simulação de si como alguém "mais santo" que o outro e de demonizar o outro como alguém que por não ser temente a Deus não pode exigir respeito como ser humano, já traz no ventre o risco maior, não calculado por quem destila esse veneno - o da autoinoculação.

De fato, no segundo turno de 2010 , não tardou muito para que o uso eleitoreiro da religião passasse a ser percebido em toda a sua indomável inconveniência. Por injunções de um final de campanha que só fazia aumentar os riscos indesejáveis que passaram a rondar a candidatura de oposição, e na intenção de evitar maiores danos ante as recentes revelações envolvendo a intimidade familiar de José Serra - todos se recordam daquele fatídico episódio: na metade de outubro, um contra-ataque dos mais reveladores atingiu diretamente a imagem de rigorosidade moral da esposa de Serra quanto à prática do aborto - o fato que aqui interessa realçar é que seu QG de campanha só então entendeu que o melhor àquela altura seria fechar duma vez a caixa de Pandora da qual jorrara aquele destampatório de agressividades que a cada dia só fazia exasperar ainda mais o turbilhão que se armara em torno do aborto. 
Tarde demais. Efeito perverso bumerangue não é um acontecer sobre o qual o agente racional possa ter algum controle ou domínio. Não dava mais para recuperar a respeitabilidade perdida. A revelação provocara no eleitor conservador e religioso, para quem um indivíduo decresce em valor quando não cumpre as obrigações convencionais que ele próprio jura defender, junto com a surpresa da verdade revelada a sensação de que estava sendo tratado como um tolo. Diante disso, um backlash como resposta à altura ficou inevitável. O leite derramara. Em sua irracionalidade insolúvel, o indecidível dilema do aborto tombara como cruel fatalidade sobre as tropas antiabortistas encasteladas na campanha da oposição, tirando delas a condição de ataque.

\section{EFEITOS COMBINADOS}

Campanha eleitoral recheada de moralismo repressivo misturado com exibicionismo devoto pode dar em efeito fariseu - eis uma lição republicana a mais para nossa jovem democracia. Uma caída na real. Essa sobering lesson, segundo a qual comporta riscos para quem dele se vale o artifício nada republicano de intumescer de particularismo religioso o direito de voto universal, essa lição nós a devemos, isto é incrível, ao eterno alvo desse tipo de tática eleitoral beata: o eleitor conservador. Como qualquer outro eleitor, ele também entra no jogo trazendo consigo a capacidade demasiado humana de se esquivar e surpreender. Imprevistamente ele vai mostrar que pode ser mais religioso, ou mais autenticamente religioso, do que julga o candidato fariseu e do que nem sequer imaginam seus desavisados coordenadores de campanha. Quando o eleitor conservador, que normalmente é um homo religiosus, percebe que sua fé está sendo exageradamente cortejada para satisfazer a interesses meramente eleitorais daquele que o bajula como um bom cristão só que em busca de benefícios próprios nem de longe religiosos, em seu fastio e indignação o que ele passa a sentir pelo candidato que assim procede só pode ser rejeição. Num gesto que tem muito de desagravo e desforra, ele pega e vota contra. No segundo turno, quando a disputa se bipolariza e esquenta, o uso eleitoreiro de um fervor religioso farisaicamente ostentado, mas facilmente contestável por revelações em contrário trazidas pelo lado adversário, não tem como deixar de transparecer como embuste inaceitável para quem tem sensibilidade religiosa, sobretudo para os que a têm à moda antiga.

$\mathrm{Na}$ noite do 31 de outubro, à medida que avançava a apuração das urnas do segundo turno, como sociólogo da religião eu ficava de olho, só esperando para ver, mas o efeito pretendido com o voto religioso não aparecia, não aparecia... Nem o empurrão de última 
hora dado pelo papa de nada adiantou. Contrariando as expectativas de quem apostara nessa tática divinamente apoiada e frustrando as expectativas dos que haviam botado a boca no trombone da internet contra um futuro iminente de aborto permitido, homofobia rechaçada e PNDH-3 aprovado e sancionado, o tratamento eleitoreiro de questões de teor moralista com fundamento religioso não conseguiu se segurar como um eixo em torno do qual se decidisse um número importante de votos. Sua relativa capacidade de persuadir durou pouco, mesmo para um jogo político de curtíssima duração.

No fim das contas, sobra ainda, desse processo eleitoral, um dado agregado que vem grifar o que tem sido o principal desafio teórico para a pesquisa sociológica da religião, na modernidade avançada de modo geral e no Brasil em particular. Refiro-me à constatação do pouco (muito pouco!) que o voto dos adeptos das diferentes igrejas cristãs foi afetado pelo muito (muito mesmo!) de orientações, doutrinações e apelações emitidas pelas autoridades católicas e evangélicas contrárias à candidata ungida por Lula e consistentemente apoiada sobre a extensa aprovação popular de seu governo. Foi muito desproporcional a diferença verificada entre o empenho mobilizador dos profissionais religiosos anti-Dilma e a plácida indiferença das maiorias religiosas a tantos apelos, incitações e aconselhamentos da parte de seus chefes religiosos. Houve recusa em ceder à pressão de uma conclamação eclesial que jogava contra os interesses individuais mais utilitários e diretamente materialistas da maioria dos brasileiros. E eram interesses materiais, não ideais, os que igualmente empurravam os fiéis praticantes a votarem pela continuidade das políticas lulistas, uma vez que também eles se sabiam atendidos por várias ações de governo nos oito anos de Lula presidente.

Isso diz muito da situação complicada em que se meteu a retórica religiosa nas democracias contemporâneas, um embaraço inextricável cuja única saída parece ser mesmo a porta de saída. É dessa perspectiva que eu ousaria dizer, para encerrar, que a enorme aceitação popular das realizações do governo Lula, com o decorrentefeel-good factor que tanto influxo exerceu na eleição presidencial de Dilma, teve também, entre outros efeitos auspiciosos, um promissor efeito secularizante.

\section{POST-SCRIPTUM}

Este artigo é uma homenagem que quero prestar uma vez mais à memória do grande sábio que foi Candido Procopio Ferreira de Camargo, meu iniciador e orientador na prática de pesquisa em sociologia da religião, no Cebrap e na Puc de São Paulo. Com ele aprendi que, na moderna orquestração do funcionamento secular da totalidade social, a religião consegue no máximo o papel de segundo violino. 
Recebido para publicação

em 30 de janeiro de 2011.

NOVOS ESTUDOS

CEBRAP

89 , março 2011

pp. 5-15
Menos, retificaria eu. Nessa eleição, a religião não podia esperar desempenhar outra coisa que um papel de figuração. Que foi afinal o que acabaram fazendo as lideranças eclesiais que engrossaram o voto em Dilma Roussef. Fizeram-no radiosamente, mas sem qualquer chance de protagonismo.

ANTÔNIO FLÁVIO PIERUCCI é professor titular do Departamento de Sociologia da FFLCH-USP. 